Original Research Article

\title{
Status of package insert guidelines for drugs accessible as over the counter drugs
}

\author{
Anuja Jha, Usha Joshi*, Rajesh Hishikar, Manju Agrawal, Ajay Halwai
}

Department of Pharmacology, Pt JNM Medical College, Raipur, Chhattisgarh, India

Received: 25 November 2017

Accepted: 28 December 2017

*Correspondence to:

Dr. Usha Joshi,

Email: ushajoshi2012@

gmail.com

Copyright: (C) the author(s), publisher and licensee Medip Academy. This is an openaccess article distributed under the terms of the Creative Commons Attribution NonCommercial License, which permits unrestricted noncommercial use, distribution, and reproduction in any medium, provided the original work is properly cited.

\begin{abstract}
Background: As per Indian pharmacopoeia, package inserts are part of a label that provides information on the article. It may be the sole source of information for drugs, which are available in the pharmacies without the prescription and it may include both prescription and over the counter (OTC) drugs. So, to aid in safety and efficacy of these drugs, package inserts must follow the standard guidelines (The Drugs and Cosmetics rule, 1945). The objective of this study was to observe the status of the standard guidelines for package insert in drugs accessible as OTC drugs.

Methods: Based on the inquiries made with pharmacies, list of drugs commonly bought without prescription was made. 256 drugs were evaluated. Their package inserts were observed for the extent to which the guidelines given by The Drugs and Cosmetics rule 1945, section 6.2 and 6.3 are being followed. Secondary objectives were made to assess if package inserts are physician friendly or patients friendly.

Results: Package inserts were missing in 180 (70\%) of the drugs. Therapeutic indications were present in $71 \%$ of the available package inserts (76). Pharmaceutical information was given in $57 \%$ of the package inserts. English was the preferred language and medicinal terms were used. Only one package insert was patient friendly.

Conclusions: Package inserts should be made available in every drug. There should be a separate patient oriented package insert guideline, as per US food and drug administration (FDA), in India as well. This will aid in their safe and effective use.
\end{abstract}

Keywords: Drugs and cosmetics Rule, Over the counter drug (OTC), Package insert

\section{INTRODUCTION}

In order to save time and money, people prefer to selfmedicate themselves for minor ailments like fever, pain, cough, and gastrointestinal disturbances. ${ }^{1}$ It starts with the home remedies and if it doesn't work, they tend towards the medical shop or internet to find a suitable treatment. Patients receive information regarding drugs from the pharmacists, drug labels, package inserts available with the drugs and internet. ${ }^{2,3}$ In India most of the pharmacists are not well trained and internet is neither reliable nor accessible to everyone. This makes package inserts an important and reliable source of information of the drug for the pharmacists and the patients. Even when there is a doctor patient interaction, patient receives oral instructions from the doctor, but it can be missed, forgotten or misunderstood.$^{4}$ In these cases also package inserts play a crucial role as they provide written and well-informed instructions which help in the efficacious use of the drug.

As per Indian pharmacopoeia, package inserts are part of label which provides information on the article. ${ }^{5}$ As per 
food and drug administration (FDA), package inserts should entail a summary for safe and effective use of the drug. They should be informative and accurate, not promotional. They should not provide any information that is false or misleading, or implies claims or suggestions for use if evidence of safety or effectiveness is lacking, based whenever possible on data derived from human experience. ${ }^{6}$ Hence package inserts help in the safe and efficacious use of drug. In India, package insert guidelines are described in drug and cosmetic act section 6.2. and 6.3. Para 6.2 provides therapeutic information of a drug. According to this, package insert should be in English. Para 6.3 provides the pharmaceutical information of a drug. ${ }^{7}$

Drugs can be broadly divided into prescription drugs and non-prescription drugs or over the counter (OTC) drugs. In India, prescription drugs come under schedule $\mathrm{H}$ and schedule $\mathrm{H} 1$ drugs. Apart from schedule $\mathrm{H}$ and $\mathrm{H} 1$, schedule $G, X$ and $J$ have been classified. ${ }^{7}$ Since there is no separate schedule for OTCs, drugs which do not fall in the above-mentioned categories, falls under OTC. As per FDA, OTC drugs are defined as drugs that are safe and effective for use by the general public without seeking treatment by a health professional. ${ }^{8}$ In India, even though there are separate regulations for prescription drugs, many of these drugs are easily accessible without a prescription.

In this study, we collected package inserts of drugs which are easily accessible as OTC from various medical shops. These package inserts were compared with the guideline provided in drug and cosmetic rule 1945 (D and C rule). ${ }^{7}$ Apart from the comparison with the standard guideline, we also looked for various factors such as legibility, use of scientific language or regional language, colour printing, spacing and references which can make a package insert patient friendly. Several studies have been conducted for package inserts, but this study specifically includes package inserts for drugs that are easily accessible as over the counter drugs which patients take as self-treatment. Package inserts play a special role in this group of medication.

\section{METHODS}

\section{Study area}

Study was conducted at department of pharmacology, Pt. JNM Medical College Raipur, Chhattisgarh. Six pharmacies were surveyed for this study. These pharmacies were located in the vicinity of Bhim Rao Ambedkar memorial hospital, which is a tertiary care hospital in Raipur.

Primary objective of this study was to compare package inserts with the standard guideline. Secondary objectives were to look for other parameters which include use of regional language, use of patient oriented or scientific language, font size or legibility, info graphics, colour printing, spacing, references, and heading. Last date of revision of text was also noted down.

\section{Study design}

It was an observational study. Based on the inquiries made with the pharmacies, a list of drugs was prepared which were brought without the prescription. It included both OTCs and prescription drugs which are accessible without prescription. Then the package inserts for these drugs were collected on request over three weeks. These package inserts were compared with the guideline given in the para 6.2 and 6.3 of drug and cosmetic rule 1945 and also for secondary objectives. Fourteen parameters from drug and cosmetic rule were compared. ${ }^{7}$ Data was analysed by descriptive statistics and results were expressed as percentage and absolute numbers. Eight parameters mentioned in the secondary objective were assigned with one point. Grading was done for secondary objectives. Grade A was ascertained for score 6 to 8 , grade B for 3 to 5 and grade $\mathrm{C}$ for 0 to 2 . Grade $\mathrm{A}$ is for patient friendly package insert, while grade $\mathrm{C}$ is physician friendly.

\section{Data collection}

256 drugs were evaluated for package inserts in drugs which were easily accessible as over the counter drugs for a period of three weeks. Out of 256, package inserts were available in 81 drugs. Five package inserts were excluded due to duplication. These 76 package inserts were evaluated for all the parameters mentioned in the objective section. We report our finding in the result section.

\section{RESULTS}

256 drugs were evaluated for package inserts. Package inserts were missing in 180 drugs $(70 \%) .76$ package inserts $(30 \%)$ were evaluated for primary and secondary objectives. They were classified on the basis of dosage forms and class of drugs (Table 1). $86.8 \%$ were oral preparation, while injectable and topical preparations were $3.9 \%$ and $9.3 \%$ respectively (Figure 1). Drugs category is summarized in the Figure 2.

Table 1: Classification of PI based on the dosage form of drugs.

\begin{tabular}{|ll|}
\hline Dosage & Total \\
\hline Tablet & 36 \\
\hline Capsule & 20 \\
\hline Syrup and suspension & 08 \\
\hline Injection & 03 \\
\hline Sachet & 01 \\
\hline Cream and ointment & 06 \\
\hline Eye drop & 01 \\
\hline Gum & 01 \\
\hline
\end{tabular}

All the drugs were analysed for primary and secondary objectives. Primary objective was to compare package 
inserts with the guideline given in the drug and cosmetic rule 1945. This guideline is divided into two main categories for therapeutic information and for pharmaceutical information. All the points mentioned in the act were summarized with the percentage of package insert which were following the guideline (Table 2 and Table 3).

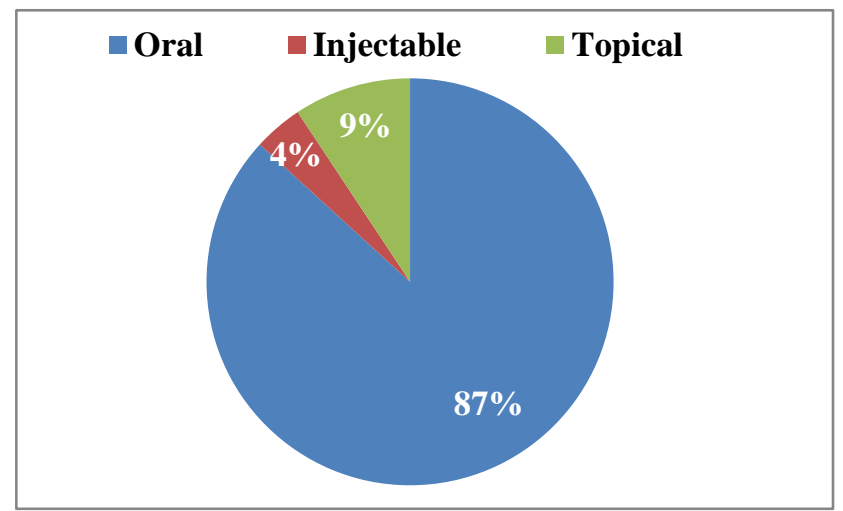

Figure 1: Classification of PI based on route of drug administration.

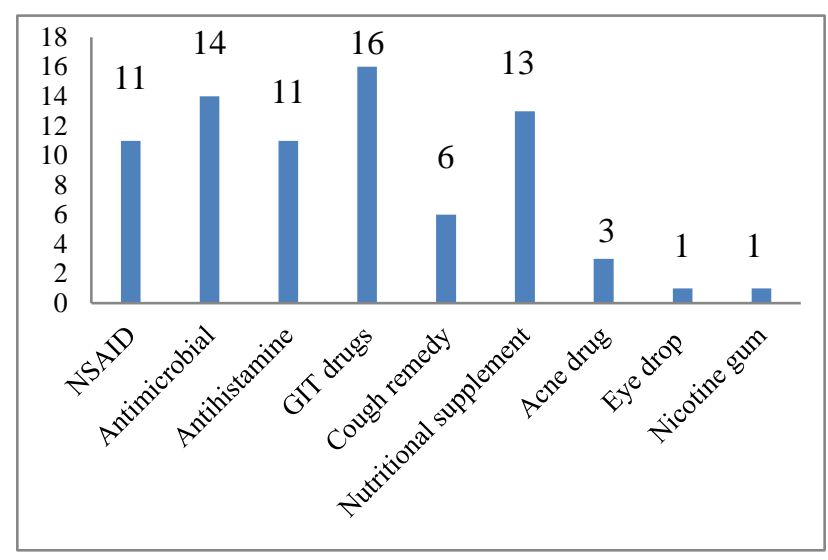

Figure 2: Classification of PI based on the drug category.

Table 2: Assessment of PI for therapeutic information.

\begin{tabular}{|l|l|}
\hline Therapeutic indication to be present & $\%$ of PI \\
\hline Posology and method of administration & 86 \\
\hline Contraindication & 84 \\
\hline Precaution & 81 \\
\hline Drug interaction & 74 \\
\hline Effect on pregnancy and lactation & 79 \\
\hline Effect on ability to drive and use of machine & 30 \\
\hline Side effects & 84 \\
\hline Antidote for overdose & 53 \\
\hline
\end{tabular}

All the package inserts were in English as required by the drug and cosmetic rule 1945. Four package inserts were in both Hindi and English. Therapeutic indications were present in more than $50 \%$ of the package inserts except for the effect on ability to drive and use of machine which was present in $30 \%$. Important instructions like posology, contraindication, precaution, drug interaction and sideeffects were present in $86 \%, 84 \%, 81 \%, 74 \%$ and $84 \%$ of package inserts respectively. While effect on pregnancy, lactation and antidote for overdose were present in 79 and $53 \%$ of package inserts respectively. Pharmaceutical information like excipient, incompatibility and shelf life were present in $35 \%, 28 \%$ and $28 \%$ respectively. Storage instructions, specification of container and instruction for use were present in $86 \%, 86 \%$ and $79 \%$ respectively.

Table 3: Assessment of PI for pharmaceutical information.

\begin{tabular}{|ll|}
\hline Pharmaceutical information & $\%$ of PI \\
\hline Excipient & 35 \\
\hline Incompatibility & 28 \\
\hline Shelf life & 28 \\
\hline Precaution for storage & 86 \\
\hline Specification of container & 86 \\
\hline Instruction for use & 79 \\
\hline
\end{tabular}

For analysis of secondary objectives drugs were categorised as grade A, B and C. Grade A is patient's friendly and grade $\mathrm{C}$ is for physician friendly. Most of the drug belonged to grade B (42) and grade C (33) category. Only one drug belonged to category A (Figure 3 ).

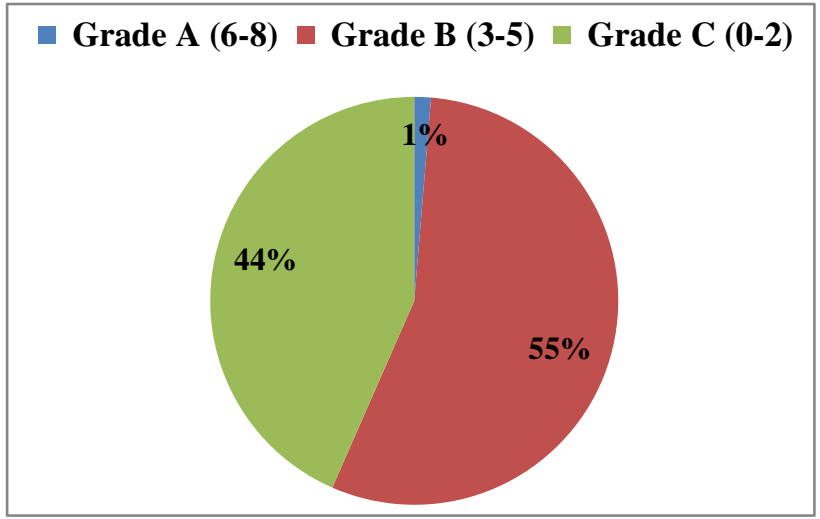

Figure 3: Assessment of PI for secondary objectives.

Drugs were also evaluated for date of revision of text. Seven package inserts $(9 \%)$ had mentioned their date of revision.

\section{DISCUSSION}

Package inserts are efficient tool which helps in the efficacious and safe use of the drugs. Therefore, regulatory authorities have made specific guidelines for package inserts.$^{4}$ In USA it is regulated by FDA whereas in India it is regulated by ministry of health and family welfare. Drug and cosmetic rule 1945 section 6.2 and 6.3 provided the guidelines in India. ${ }^{7}$ 
In present study, package inserts were present in $30 \%$ of the entire drug evaluated. In the rest $70 \%$ drugs which are accessible as OTC, package inserts were missing. It shows poor compliance by the pharmaceutical companies. In cases where package inserts were present, guidelines have not been followed completely. Therapeutic indications were present in $71 \%$ cases while pharmaceutical information was present in $57 \%$ cases. This shows a lack of adherence to guideline. Important aspects of a drug usage such as method of drug administration, side-effects, contraindications and precautions were present in more than $80 \%$ of package inserts. $79 \%$ package inserts had mentioned about the effect of drug on pregnancy and lactation. It is an important category as many drugs can have adverse effect on the pregnancy and can be secreted in the milk. ${ }^{9}$ Apart from this, shelf life was mentioned in only $28 \%$. Drugs can be less efficacious after the shelf life, so this information should be present in all package inserts. ${ }^{10}$

Secondary objectives were established to find out whether the information contained in the package inserts are intended for physicians or for the patients. Grading was done for this and only one drug was found to be patient oriented. Indian guideline lacks the clarification on whether package inserts are physicians friendly or the patients friendly. According to regulations, package inserts should be in English which makes it physician friendly.

Gibbs et al study, a national survey, showed that $97 \%$ patient wanted to receive patient information leaflet with the drug. They also found that patients who had received package insert were more satisfied than those who did not. ${ }^{11}$ Another study by Gibbs et al showed patients who had received package inserts were more compliant with the treatment. They were more knowledgeable about their disease and the treatment. ${ }^{12}$ In India study has shown that patients want to read the package inserts. ${ }^{13}$ Therefore there should be a separate package inserts for the patients which should be given in the regional language. These package inserts should aim at being more patient friendly by minimal use of scientific language and they should be easily readable with proper spacing and heading. All the presented information should be clear. Info graphics and use of different colours in the package inserts will make them more attractive for the patients. Info graphics or use of pictures will be beneficial in the geriatrics group of patients as most of these patients have difficulty in reading. Use of pictures or visual aids makes it easier to communicate to an educationally diverse population. ${ }^{14}$

Date of revision of text was present in only seven package inserts (9\%). This information should be made mandatory as it provides validity and authenticity to the package inserts which is applicable for both the physicians and the patients. This will also help in the addition of any updates regarding the drug. Any post marketing surveillance reports can be added after revision.
In India there is a common guideline for package insert for both OTCs and prescription drugs even when OTCs are used without doctor's instruction. Special category such as the extremes of age, pregnancy and lactation are more vulnerable to harm from drugs including OTCs. ${ }^{15}$ There can be dangerous or life-threatening drug interactions between two OTCs or between OTC and a prescription drug which is prescribed for another ailment. Sometimes OTCs drug which are used to treat two different conditions may contain overlapping active ingredient. There are more chances of adverse drug reaction with the self-treatment than the prescription based treatment. ${ }^{16}$ Some active ingredients like antihistamines and laxatives which are present in OTCs are liable for abuse. ${ }^{17,18}$ There should be separate warning for this on the package inserts. In developed countries like USA, FDA has provided separate guideline for OTCs.

\section{CONCLUSION}

In conclusion there should be a separate schedule for OTC drugs and guidelines for their package inserts. This guideline should be strictly followed, and pharmaceutical companies should be adherent to it. Package inserts should be made available in all the drugs. There is also need for stringency for prescription drugs which are available without prescription.

\section{ACKNOWLEDGEMENTS}

Authors would like to thank all the pharmacies which helped in the completion of this study.

Funding: No funding sources

Conflict of interest: None declared

Ethical approval: The study was approved by the Institutional Ethics Committee

\section{REFERENCES}

1. Parikh D, Sattigeri BM, Kumar A, Brahmbhatt S. A survey study on use of over the counter (OTC) drugs among medical students, nursing and clerical staff of a tertiary care teaching rural hospital. Int J Res Med Sci. 2017;1(2):83-6.

2. Hsämeen-Anttila K, Nordeng H, Kokki E, Jyrkkä J, Lupattelli A, Vainio K, et al. Multiple information sources and consequences of conflicting information about medicine use during pregnancy: a multinational Internet-based survey. J Med Int Res. 2014;16(2).

3. Diaz JA, Griffith RA, Ng JJ, Reinert SE, Friedmann PD, Moulton AW. Patients' use of the Internet for medical information. $\mathbf{J}$ General Internal Med. 2002;17(3):180-5.

4. Dass AS, Sarala N, Bhuvana K. Analysis of Package Inserts of Drugs Utilized in a Tertiary Care Hospital. J Young Pharmacists. 2016;8(3):275-8.

5. Indian Pharmacopoeia 2007. Available at: http://ajprd.com/downloadebooks_pdf/9.pdf. Accessed 25 December 2017. 
6. Food and drug administration. An Introduction to the Improved FDA Prescription Drug Labeling. Available at: https://www.fda.gov/downloads/training/forhealthpro fessionals/ucm090796.pdf. Accessed 24 November 2017.

7. Central Drugs Standard Control Organization. The drugs and cosmetics act and rules. Available at: http://www.cdsco.nic.in/writereaddata/2016Drugs\%2 0and\%20Cosmetics\%20Act\%201940\%20and\%20Ru les\%201945.pdf. Accessed 25 November 2017.

8. Food and drug administration. Drug Applications for Over-the-Counter (OTC) Drugs. Available at: https://www.fda.gov/Drugs/DevelopmentApprovalPr ocess/HowDrugsareDevelopedandApproved/Approv alApplications/Over-the-CounterDrugs/default.htm. Accessed 24 November 2017.

9. Menon SJ. Psychotropic medication during pregnancy and lactation. Arch Gynecol Obstet. 2008;277(1):1-3.

10. Cantrell L, Suchard JR, Wu A, Gerona RR. Stability of active ingredients in long-expired prescription medications. Arch Int Med. 2012;172(21):1685-7.

11. Gibbs S, Waters WE, George CF. Prescription information leaflets: a national survey. J Royal Soci Med. 1990;83(5):292-7.

12. Gibbs SH, Waters WE, George CF. The benefits of prescription information leaflets (2). $\mathrm{Br} \mathrm{J}$ Clin Pharmacol. 1989;28(3):345-51.
13. Bansal V, Dhamija P, Medhi B, Pandhi P. Package inserts-do they have any role. JK-Practitioner. 2006;13(3):152-4.

14. Cunningham MR. Revolutionizing the Patient Package Insert with Infographics. BU Well. 2016;1(1):5.

15. Davis JE. Are one or two dangerous? Methyl salicylate exposure in toddlers. J Emerg Med. 2007;32(1):63-9.

16. Panda A, Pradhan S, Mohapatra G, Mohapatra J. Drug-related problems associated with selfmedication and medication guided by prescription: A pharmacy-based survey. Indian J Pharmacol. 2016;48(5):515.

17. Malcolm R, Miller WC. Dimenhydrinate (Dramamine) abuse: hallucinogenic experiences with a proprietary antihistamine. Am J Psychiat. 1972;128(8):1012-3.

18. Serrano-Falcon B, Rey E. The safety of available treatments for chronic constipation. Expert Opinion on Drug Safety. 2017;16(11):1243-53.

Cite this article as: Jha A, Joshi U, Hishikar R, Agrawal M, Halwai A. Status of package insert guidelines for drugs accessible as over the counter drugs. Int J Basic Clin Pharmacol 2018;7:298-302. 